(c) American Dairy Science Association, 2004.

\title{
A Complete Genome Scan of the Israeli Holstein Population for Quantitative Trait Loci by a Daughter Design
}

\author{
M. Ron, ${ }^{1}$ E. Feldmesser, ${ }^{1}$ M. Golik, ${ }^{1}$ I. Tager-Cohen, ${ }^{1}$ D. Kliger, ${ }^{1}$ V. Reiss, ${ }^{1}$ \\ R. Domochovsky, ${ }^{1}$ O. Alus, ${ }^{1}$ E. Seroussi, ${ }^{1}$ E. Ezra, ${ }^{2}$ and J. I. Weller ${ }^{1}$ \\ ${ }^{1}$ Institute of Animal Sciences \\ ARO, The Volcani Center \\ Bet Dagan 50250, Israel \\ ${ }^{2}$ Israel Cattle Breeders Association \\ Caesaria Industrial Park \\ Caesaria 38900, Israel
}

\section{ABSTRACT}

Eleven Israeli Holstein families including 5221 cows were analyzed by a daughter design for eight economic traits: milk, fat and protein production, fat and protein percentage, somatic cell score (SCS), herd-life, and female fertility. The cows were genotyped for 73 microsatellites with maximum spacing between markers of 53 cM. There were 86,304 informative genotypes. Preliminary analysis was by ANOVA of each trait, with the marker effect nested within sire. Significance was determined by controlling the false discovery rate at 0.4 , after excluding markers with genome-wide significance for at least a single trait, and traits without any significant effects at this level. Thus, four markers on chromosomes 6 and 14 and female fertility were excluded. There remained 40 significant marker-trait combinations, and it is expected that 24 of these are true effects. To perform interval mapping for the families with significant contrasts, 21 additional markers were genotyped on chromosomes 2,7 , and 27 . The bootstrap confidence intervals for gene effect did not include zero for protein percent on chromosome 2 and fat yield, protein yield, and SCS on chromosome 7. Quantitative trait locus heterozygosity was $33 \%$, which is consistent with the hypothesis that only two alleles are segregating with unequal allele frequency.

(Key words: cattle microsatellite, genome scan, quantitative trait locus, daughter design)

Abbreviation key: BTA $=$ Bos taurus autosome, CI95 $=95 \%$ confidence intervals, $\mathbf{F D R}=$ false discovery rate.

\section{INTRODUCTION}

Many studies have shown that individual QTL can be detected and mapped in commercial dairy cattle pop-

Received October 20, 2002.

Accepted June 1, 2003.

Corresponding author: J. I. Weller; e-mail: weller@agri.huji.ac.il. ulations with the aid of genetic markers by application of daughter or granddaughter designs. The granddaughter design has the advantages that it is more powerful per genotyped individual, and it is logistically easier to collect genetic material from AI sires located at a few studs, as opposed to cows, which are scattered over a much larger number of herds (Weller et al., 1990). However, the required population structure for the granddaughter design (several sires, each with many progeny-tested sons) is available only in the largest commercial populations. The appropriate population structure for the daughter design (several sires, each with hundreds of milk-recorded daughters) can also be found in populations of moderate size, such as the Israeli Holsteins, or US breeds other than Holstein. Although daughter designs are less powerful than granddaughter designs per individual genotyped, potentially many more daughters are available for analysis, even in populations of moderate size. For moderately heritable traits, it is necessary to genotype approximately 4 times as many individuals with a daughter design, compared with a granddaughter design to obtain the same statistical power. However, at most, only a few hundred progeny-tested sons are available for analysis from a single grandsire family, even in the largest populations (Heyen et al., 1999), whereas thousands of daughters of a single sire have genetic evaluations, even in populations of moderate size. Furthermore, with multiple records per cow, the relative advantage of the granddaughter design decreases, especially for high heritability traits (Weller et al., 1990).

In most granddaughter design analyses to date, the limiting factor has been the number of sons available for analysis. Therefore most of these analyses have used average marker spacings in the range of $40 \mathrm{cM}$ (e. g., Heyen et al., 1999). Over 100 markers are required to obtain this level of coverage for the bovine genome. In a daughter design analysis, the number of individuals available for genotyping with records on production traits is no longer limiting. The limiting factor is the 
cost of the total number of genotypes. In this case, statistical power relative to costs is maximized by a relatively wide marker spacing (Darvasi and Soller, 1994).

A major problem with complete genome scans is determining the appropriate type I error rate to declare significance. In complete genome scans, a probability of $5 \times 10^{-5}$ is required to obtain an experiment-wise type I error rate of 0.05 for a single trait (Weller, 2001). If multiple traits are analyzed, this probability must be reduced proportionately to obtain the same experimentwise type I error rate. If such low probabilities are required to determine significance, then many true effects of economic importance will be missed. Various solutions have been proposed to overcome this problem. Weller et al. (1998) proposed applying the false discovery rate (FDR) of Binjamini and Hochberg (1995), and several recent studies have used this approach (Heyen et al., 1999; Mosig et al., 2001).

A question that has not been considered previously is how the FDR should be applied when several clearly significant effects are included in the analysis. These effects will tend to reduce the FDR at any specific level. This problem is more acute if several linked markers all detect the same effect. A second question that should be considered in multitrait analyses is related to differences in heritability of the traits analyzed. Weller et al. (1990) showed that for a given experiment size the number of detectable effects will be a function of the trait heritability. Thus, for traits with low heritability, no detectable effects are expected, and inclusion of these traits in the analysis will increase the false discovery rate. A solution to these problems will be presented.

The goal of this study is to present the results of a complete genome daughter design analysis of the Israeli Holstein population for 8 economic traits; milk, fat, and protein production; fat and protein percentage; SCS; herd-life; and female fertility. Results for Bos taurus autosomes (BTA) 6 and 14 have been presented previously (Heyen et al., 1999; Ron et al., 2001, Weller et al., 2003).

\section{MATERIALS AND METHODS}

\section{Genotyping Methods}

From 1995 through 1999 blood samples were collected in 233 herds from approximately 13,000 IsraeliHolstein cows, putative daughters of 11 sires. Three to five milliliters of blood from the jugular vein of cows was collected by Vacutainer tubes with heparin anticoagulant (Becton Dickinson, Franklin Lakes, NJ). Frozen semen of the 11 Israeli-Holstein sires was obtained from the Sion AI institute. The DNA from frozen blood or semen was extracted by the salting out procedure (Ma et al., 1996). Cow DNA was stored at $-20^{\circ} \mathrm{C}$ in deep 1-ml 96-well plates (Beckman, CA) at a concentration of $7 \mathrm{ng} / \mu \mathrm{l}$. Five microliters of DNA was aliquoted to 96well and 384-well plates (Robbins Scientific, Sunnyvale, CA) using Hydra robotic dispenser (Robbins Scientific). The DNA in plates was dried down and stored at room temperature, ready for subsequent PCR. All cow samples on a plate were putative daughters of the same sire. Two positions in different halves of the plate were left blank without DNA, as negative controls. Three other positions, two in the second half of the plate, contained DNA of the sire as positive controls and for orientation of the plate. The PCR protocols for DNA isolated from semen and blood cells were as described by Ron et al. (1995) using a DNA engine thermocycler (MJ Research, Inc., Waltham, MA).

Seventy-three microsatellites were run in six panels. The ABI 377 DNA sequencer (Applied Biosystems, Foster, City, CA) is capable of reading up to 4 dyes in each lane, thereby permitting "multiplexing" of the samples. Each panel of microsatellites was based on 3 to 5 multiplexed PCR reactions of fluorescent-labeled microsatellites. Annealing temperatures of PCR ranged from 55 to 66 degrees, with 30 cycles of amplification. Each multiplex PCR included 2 to 5 markers. Each microsatellite panel was designed so that the alleles of markers labeled with the same color dye would not overlap in the same size range when run in a single lane of a polyacrylamide gel. Microsatellites were first chosen to obtain complete coverage of the bovine genome with a maximum spacing of $50 \mathrm{cM}$ between markers. Additional selection criteria were ease of scoring, mean heterozygosity, and appropriate fragment size relative to the other microsatellites included in each panel.

Two microliters from each one of the different PCR of the same panel were pooled using the Hydra robotic dispenser (Robbins Scientific). One microliter of each pool was added to $0.6 \mu \mathrm{l}$ of loading buffer $(75 \%$ formamide/blue dextran dye, 25\% MapMarker Low, BioVentures, TN), loaded on a 48-lane gels using an 8channel loader (Hamilton, NE), and run on the ABI 377 DNA sequencer. Automated fragment analysis, size calling, and binning were then used by GeneScan (Version 3.1) and Genotyper (Version 2.0) genetic softwares (Applied Biosystems) to identify the alleles of each of the microsatellite loci. A second quality check of the genotype data was performed manually by an independent worker.

\section{Analysis of Genotypes}

We applied a two-step procedure. In the first step several hundred cows from each family were genotyped with a mean marker spacing of approximately $50 \mathrm{cM}$. Cows with invalidated paternity, as described in the 
following paragraphs, or without genetic evaluations, were deleted from further analysis. Statistical significance was determined by ANOVA for each marker, as will be described in the "statistical methods" section. In the second step, progeny of families with significant contrasts for specific markers were genotyped for additional markers linked to the markers with significant effects to perform interval mapping, taking into account missing or uninformative genotypes (Knott et al., 1996).

The rules of Mendelian inheritance require that, baring mutation, each parent and progeny should share at least one common allele. Discrepancies between the cow and putative sire genotypes may be due to mutation, errors in genotyping, or errors in paternity recording. Cows with incorrect paternity should be excluded from further analysis, but not cows with a mutation or an erroneous genotype for a specific marker. Our genome scan included more than 160,000 individual marker genotypes, and a dataset of this magnitude will contain both erroneous genotypes and mutations. Previous studies have shown that mutation rates for microsatellites are insignificant relative to errors in paternity recording (Crawford and Cuthbertson, 1996; Ron et al., 1996). The rate of erroneous genotypes in large datasets has not been studied in detail. Based on these considerations, a set of filtering criteria were devised to exclude cows and genotypes from analysis.

Cows without valid genotypes for less than 5 microsatellites were deleted from the analysis, because generally paternity could not be validated with a probability of at least 90\% (Ron et al., 1996). 49 Cows ( $\mathrm{n}=5949)$ were genotyped for at least 5 microsatellites. If no discrepancies were found between the putative daughter and sire genotypes, then paternity recording was assumed to be correct. If two or more discrepancies were found, then the listed paternity was assumed to be incorrect, and this cow was deleted from further analysis. At least 10 markers were genotyped for all cows with a single discrepancy between the cow's genotype and that of her sire. Cows that did not inherit either paternal allele for at least 2 loci were considered not to be daughters of the sire listed, unless the cow was genotyped for more than 20 microsatellites. In this case, paternity was assumed to be incorrect if there was a discrepancy between the cow and putative sire genotypes in more than $10 \%$ of the microsatellites, or at least 3 microsatellites. If there was a discrepancy in only a single marker, or in only 2 markers for cows with valid genotypes for at least 20 markers, we assumed that these discrepancies were due either to a mutation in the specific marker, or genotyping mistakes. The remaining markers of these cows were included in the QTL analyses. A total of 688 cows (11.6\%) were deleted because of incorrect paternity. Forty cows without ge-
Table 1. The numbers of confirmed daughters of each sire with valid genotypes included in the analysis.

\begin{tabular}{lcc}
\hline SIRE & Daughters & Percent \\
\hline 2278 & 682 & 13.1 \\
2283 & 419 & 8.0 \\
2357 & 515 & 9.9 \\
3070 & 693 & 13.3 \\
3089 & 509 & 9.7 \\
3099 & 240 & 4.6 \\
3208 & 502 & 9.6 \\
3212 & 422 & 8.1 \\
3241 & 595 & 11.4 \\
3258 & 334 & 6.4 \\
3274 & 310 & 5.9 \\
Total & 5221 & 100 \\
\hline
\end{tabular}

netic evaluations for all 5 production traits: milk, fat, and protein production; and fat and protein percentage were also deleted from the QTL analyses. The total number of cows genotyped from each family, after deletion of cows with incorrect paternity and without genetic evaluations, is given in Table 1.

The number of microsatellites in each panel, the number of cows with confirmed paternity genotyped for each panel, and the total number of genotypes are given in Table 2 . On average, 3010 cows were genotyped for each panel. If all genotypes were readable, then the number of individual genotypes should be the sum of the number of cows genotyped in each panel times the number of markers per panel. This is listed in the table as the "expected" number of genotypes. "Genotyping efficiency" is defined as the ratio of readable genotypes to the expected number of genotypes. Of a total of 219,685 expected genotypes, 163,733 were readable, for a genotyping efficiency of $75 \%$.

The marker panels were optimized by varying the number of markers per multiplex, the primers concentration of the different microsatellites in a multiplex, and the annealing temperatures of the different multiplexes. Including 11 to 15 markers per panel using several multiplex PCR increased throughput substantially, but decreased genotyping efficiency, due to a reduction in the signals of some markers or specific alleles. The six panels were numbered according to the chronological order of their development and use. The first three panels had genotyping efficiency of 78 to $89 \%$, whereas the latter three had efficiency between 61 to $79 \%$ (Table 2). The choice of markers for the latter three panels was determined by the need to fill the gaps in coverage of the genome map. Thus, some markers with lower efficiency were included in the latter panels, because they were the best markers available in the required map locations. An alternative explanation for the reduction in efficiency of the latter panels could 
Table 2. The number of microsatellites in each panel, the number of cows genotyped for each panel, and the total number of expected and readable genotypes.

\begin{tabular}{lllccc}
\hline \multirow{2}{*}{$\begin{array}{l}\text { Microsatellite } \\
\text { Panel }\end{array}$} & $\begin{array}{l}\text { Number of } \\
\text { markers }\end{array}$ & $\begin{array}{l}\text { Number of } \\
\text { cows }\end{array}$ & \begin{tabular}{c} 
Number of genotypes \\
\cline { 4 - 5 } Expected $^{1}$
\end{tabular} & $\begin{array}{l}\text { Readable } \\
\text { Efficiency }\end{array}$ \\
\hline 1 & 15 & 2629 & 39,435 & 31,723 & 80 \\
2 & 10 & 2487 & 24,870 & 22,222 & 89 \\
3 & 11 & 3317 & 36,487 & 28,579 & 78 \\
4 & 14 & 3229 & 45,206 & 27,531 & 61 \\
5 & 12 & 3287 & 39,444 & 31,055 & 79 \\
6 & 11 & 3113 & 34,243 & 22,793 & 67 \\
Totals/mean $^{3}$ & 73 & $(3010)$ & 219,685 & 163,733 & $(75)$ \\
\hline
\end{tabular}

${ }^{1}$ Number of markers $\times$ number of cows.

${ }^{2}$ Readable/Expected genotypes.

${ }^{3}$ Column means where totals are inappropriate are given in parentheses.

be that the DNA was somewhat degraded over time. However, efficiency was nearly equal for panels 1 and 5 .

The map locations of the markers genotyped, based on the Clay Center genetic map (http://sol.marc.usda.gov/genome/cattle/cattle.html), the number of sires genotyped, and the number of heterozygous sires per marker, and the number of informative daughters per marker are given in Table 3 . The mean number of sires genotyped per marker was 8.6, and the mean number of heterozygous sires was 5.9. Thus the mean frequency of heterozygous sires among genotyped sires was $69 \%$. Of the readable genotypes, 110,558 genotypes were for cows that were daughters of heterozygous sires (68\%). Genotypes are considered "informative" if the daughter genotype was different from her sire's genotype (Ron et al., 1996). Of the genotypes of daughters of heterozygous sires, 86,304 genotypes were informative (78\% of the genotypes of heterozygous sires, and $50 \%$ of all readable genotypes). The mean number of informative genotypes per marker was 1182 .

\section{Phenotypic Records}

The official Israeli Holstein genetic evaluations are computed twice yearly at the Agricultural Research Organization. The February, 2002, estimated breeding values for $305-\mathrm{d}$ milk, fat, and protein production, preadjusted for calving age and month, were analyzed by a repeatability animal model (Weller et al., 1994). The genetic base for all traits was the mean breeding value of cows born in 1995. Genetic evaluations for fat and protein percentage for each cow were derived as in Ron et al. (2001). The methods for genetic analysis of SCS and fertility are given in Weller and Ezra (1997), and the methods for genetic analysis of herd-life are given in Settar and Weller (1999). Means, standard deviations, and minimum and maximum values of estimated breeding values of the cows genotyped for the 8 traits analyzed are given in Table 4 , and the correlations among the evaluations are given in Table 5. There were 4 correlations with absolute values greater than 0.5 ; milk and protein yield, milk yield with both fat and protein percent, and fat yield with fat percent. Reliabilities of the estimated cow breeding values ranged from 35 to $69 \%$, with a mean of $57 \%$ and a standard deviation of $3.7 \%$.

\section{Statistical Methods}

Preliminary QTL analysis for all markers was by the following model:

$$
\mathrm{BV}_{\mathrm{ijkl}}=\mathrm{S}_{\mathrm{ij}}+\mathrm{M}_{\mathrm{ijk}}+\mathrm{e}_{\mathrm{ijk} \mathrm{l}}
$$

where $\mathrm{BV}_{\mathrm{ijkl}}$ is the $\mathrm{EBV}$ for trait $\mathrm{i}$ of cow l, daughter of sire $\mathrm{j}$, that received paternal allele $\mathrm{k} ; \mathrm{S}_{\mathrm{ij}}$ is the effect of sire $\mathrm{j}$ on trait $\mathrm{i} ; \mathrm{M}_{\mathrm{ijk}}$ is the effect of paternal allele $\mathrm{k}$ of sire $j$ on trait $i$, and $e_{i j k l}$ is the random residual associated with each record. A significant paternal allele effect is indicative of a segregating QTL linked to the genetic marker.

Critical values for significance were determined by the FDR (Benjamini and Hochberg, 1995) as proposed by Weller et al. (1998) for QTL detection. The objective in controlling the FDR is to try to minimize the FDR, while at the same time maximizing the expected number of true effects. As shown by Weller et al. (1998), the FDR for QTL analysis is a nonlinear function of both the number of null hypotheses rejected, and the nominal probability of rejection. Therefore, in some cases, a slight increase in the number of rejected hypotheses can dramatically increase both the FDR and the nominal probability of rejection. The appropriate value for controlling the FDR was therefore determined by inspecting the number of rejected null hypotheses, and the highest comparison-wise probability of the rejected hypotheses with the FDR controlled over the range of zero to 0.5 . Preliminary analysis showed that 
RON ET AL.

Table 3. The map locations of the markers genotyped, the panel, the number of sires genotyped and heterozygous sires per marker, and the number of informative daughters per marker.

\begin{tabular}{|c|c|c|c|c|c|c|}
\hline \multirow[b]{2}{*}{ Locus $^{1}$} & \multirow[b]{2}{*}{ Panel } & \multirow[b]{2}{*}{$\mathrm{BTA}^{2}$} & \multirow{2}{*}{$\begin{array}{l}\text { Map } \\
\text { location }^{3}\end{array}$} & \multicolumn{2}{|c|}{ Sires } & \multirow{2}{*}{$\begin{array}{l}\text { Informative } \\
\text { daughters }\end{array}$} \\
\hline & & & & Genotyped & Heterozygous & \\
\hline BM4307 & 6 & 1 & 35.2 & 9 & 8 & 1040 \\
\hline INRA049 & 5 & 1 & 67.5 & 9 & 7 & 1027 \\
\hline BM1824 & 2 & $1(142)$ & 108.6 & 9 & 6 & 1264 \\
\hline ETH121 & 4 & 2 & 34 & 10 & 9 & 1573 \\
\hline BMS1126 & 4 & 2 & 56 & 10 & 6 & 1238 \\
\hline BM2113* & 2 & $2(121)$ & 106.2 & 9 & 9 & 2413 \\
\hline UWCA7 & 5 & 3 & 19.9 & 9 & 8 & 1588 \\
\hline INRA003* & 3 & 3 & 59.5 & 11 & 7 & 1593 \\
\hline HUJII77* & 5 & 3 & 87.4 & 10 & 3 & 596 \\
\hline INRA200* & 6 & $3(125)$ & 109.7 & 8 & 3 & 513 \\
\hline RM188* & 3 & 4 & 24.7 & 11 & 6 & 1679 \\
\hline BM6458 & 5 & 4 (101) & 68.3 & 10 & 9 & 1373 \\
\hline BP1 & 4 & 5 & 19 & 10 & 7 & 1364 \\
\hline ETH10* & 2 & $5(122)$ & 70 & 9 & 6 & 898 \\
\hline BM143* & 2 & 6 & 49.4 & 9 & 8 & 1979 \\
\hline BM415* & 2 & $6(126)$ & 76.3 & 9 & 8 & 1581 \\
\hline RM006* & 1 & 7 & 22.1 & 7 & 4 & 739 \\
\hline UWCA20* & 1 & 7 & 59.9 & 7 & 7 & 1909 \\
\hline ILSTS006 & 3 & 7 (134) & 116 & 11 & 8 & 2059 \\
\hline BMS1591 & 5 & 8 & 28.1 & 10 & 8 & 1575 \\
\hline BMS1341* & 3 & 8 & 51.4 & 11 & 5 & 1096 \\
\hline BM711 & 1 & $8(116)$ & 83.6 & 7 & 5 & 847 \\
\hline BM757* & 1 & 9 & 0.6 & 7 & 5 & 1266 \\
\hline ETH225 & 1 & 9 & 8.1 & 7 & 2 & 677 \\
\hline UWCA9 & 3 & 9 & 44.9 & 3 & 2 & 164 \\
\hline BMS1290 & 3 & 9 & 59 & 11 & 8 & 2152 \\
\hline BMS2295* & 6 & 9 (109) & 91.5 & 9 & 8 & 1151 \\
\hline BRN & 5 & 10 & 29.2 & 10 & 9 & 1218 \\
\hline BMS1318* & 4 & 10 & 73 & 9 & 7 & 1052 \\
\hline RM096* & 4 & 11 & 31 & 8 & 5 & 960 \\
\hline BM8118* & 6 & 11 & 72.4 & 9 & 6 & 1333 \\
\hline HEL13 & 4 & 11 (124) & 114 & 9 & 6 & 702 \\
\hline IDVGA57* & 5 & 12 & 29.9 & 10 & 6 & 1007 \\
\hline BM860* & 1 & 12 & 49.4 & 7 & 6 & 1145 \\
\hline BM4028* & 1 & $12(106)$ & 79.7 & 7 & 3 & 785 \\
\hline BMC1222 & 4 & 13 & 20 & 10 & 8 & 1374 \\
\hline BMS1352* & 4 & 13 & 31 & 7 & 6 & 1273 \\
\hline BMS995* & 3 & $13(87)$ & 84.1 & 11 & 4 & 890 \\
\hline ILSTS039* & 2 & 14 & n. 1. & 7 & 7 & 1453 \\
\hline CSSM66* & 1 & 14 & n. 1 . & 7 & 8 & 2501 \\
\hline BM4305 & 4 & $14(87)$ & 66.4 & 7 & 3 & 539 \\
\hline BMS2684 & 3 & 15 & 34.9 & 9 & 2 & 554 \\
\hline HBB* & 1 & 15 & 39.6 & 7 & 4 & 942 \\
\hline SPS115* & 2 & 15 (94) & 70 & 8 & 4 & 589 \\
\hline TGLA245 & 6 & 16 & 6.5 & 5 & 3 & 343 \\
\hline IDVGA68* & 5 & 16 & 47.4 & 9 & 7 & 1148 \\
\hline INRA13 & 4 & $16(93)$ & 88 & 3 & 3 & 294 \\
\hline BMS2220 & 4 & 17 & 16 & 8 & 6 & 719 \\
\hline IDVGA40 & 6 & $17(99)$ & 67 & 9 & 6 & 1241 \\
\hline BM7109 & 5 & 18 & 49.6 & 10 & 5 & 795 \\
\hline TGLA227* & 2 & $18(85)$ & 84.7 & 9 & 7 & 1572 \\
\hline BMS745* & 6 & 19 & 15.9 & 8 & 5 & 1004 \\
\hline BP20 & 1 & 19 & 46.5 & 7 & 6 & 1128 \\
\hline IDVGA48 & 6 & $19(100)$ & 70.7 & 9 & 8 & 1215 \\
\hline BM1225* & 1 & 20 & 8 & 7 & 3 & 673 \\
\hline TGLA126 & 2 & 20 & 31.2 & 9 & 4 & 679 \\
\hline BM5004* & 6 & 20 & 64.3 & 9 & 6 & 1178 \\
\hline ETH131* & 1 & 21 & 32.3 & 6 & 5 & 1122 \\
\hline TGLA122 & 2 & 21 (89) & 67.3 & 9 & 8 & 1653 \\
\hline CSSM $41 *$ & 1 & $22(79)$ & 46.3 & 7 & 3 & 468 \\
\hline CYP21 & 1 & $23(67)$ & 36 & 7 & 4 & 815 \\
\hline BM7151* & 6 & 24 & 6 & 9 & 8 & 1363 \\
\hline BMS466 & 4 & $24(62)$ & 46 & 9 & 7 & 1480 \\
\hline ILSTS102* & 5 & 25 & 6.5 & 10 & 10 & 2168 \\
\hline & & & & & & Continued \\
\hline
\end{tabular}


Table 3. Continued The map locations of the markers genotyped, the panel, the number of sires genotyped and heterozygous sires per marker, and the number of informative daughters per marker.

\begin{tabular}{llllllc}
\hline & & & & \multicolumn{2}{c}{ Sires } & \\
\cline { 5 - 6 } Locus $^{1}$ & Panel & BTA $^{2}$ & $\begin{array}{l}\text { Map } \\
\text { location }\end{array}$ & Genotyped & Heterozygous & $\begin{array}{l}\text { Informative } \\
\text { daughters }\end{array}$ \\
\hline BMS1353 & 5 & $25(65)$ & 45.3 & 9 & 4 & 775 \\
BMS651* & 5 & 26 & 2.5 & 10 & 9 & 1802 \\
BM4505 & 4 & $26(72)$ & 40 & 10 & 9 & 1621 \\
BMS2168 & 3 & 27 & 0 & 11 & 6 & 1509 \\
BMS689* & 3 & $27(64)$ & 34.1 & 11 & 7 & 513 \\
BMC6020 & 4 & 28 & 2 & 5 & 3 & 1214 \\
IDVGA43* & 6 & $28(52)$ & 27.9 & 9 & 6 & 1036 \\
ARO26 & 1 & 29 & 11 & 7 & 5 & 954 \\
BMC6004* & 3 & $29(65)$ & 57.9 & 10 & 5 & 1182 \\
Means & & & & 8.6 & 5.9 & \\
\hline
\end{tabular}

${ }^{1}$ Markers with significant effects on at least one trait are denoted by an asterisk (see Table 8).

${ }^{2}$ The chromosome length in CM is given for the last marker in parenthesis.

${ }^{3}$ Based on the Clay Center genetic map: http://sol.marc.usda.gov/genome/cattle/cattle.html. Two markers not listed on this map are denoted "n. l.", and their map positions are given in Grisart et al. (2002).

there was a major jump in the nominal probability of rejected hypotheses when the FDR was increased above 0.4. Therefore, the FDR was controlled at this level. The FDR was first computed for all traits jointly. Markers that met the nominal genome-wide significance level of $P<10^{-5}$ for at least one trait, and were declared significant in previous studies on Holsteins for the same trait, were deleted from computation of the FDR. Because these marker-trait combinations met the criterion of "confirmed linkage" (Lander and Kruglyak, 1995), their inclusion in the analysis would artificially reduce the FDR.

For polygenic traits with heritability below 0.05 , it is unlikely that any individual QTL could be detected with an experiment of this size (Weller et al., 1990). As noted previously, inclusion of these traits in the analysis would artificially increase the FDR. Therefore, the FDR was then computed for each trait separately, and traits that did not meet the FDR level of 0.4 for any marker were deleted from further analysis. The critical probability for controlling the FDR at 0.4 in the multitrait analysis was then recomputed, with the total number of comparisons corrected to account for the comparisons that were deleted.
For those markers with significant effects on the economic traits, additional linked markers were genotyped in the daughters of the sires with "significant" contrasts on BTA 2, 7, and 27. The type I error rate for significance of the within family contrasts was set at 0.05 , but significance was considered only for marker-trait combinations with across-family significance by the FDR criterion. The additional markers genotyped only on the families with significant effects are given in Table 6 . For comparison, the markers genotyped on these chromosomes in the complete genome scan are also listed. Map distances between the markers were computed by the "fixed" option of "Crimap" (http://linkage.rockefeller.edu/soft/crimap/), using the marker order as determined by the Clay Center map. The map locations, based on the Clay Center map, and the Crimap analysis are also listed in Table 6. The crimap genetic maps were longer for BTA 2 and BTA 7, and slightly shorter for BTA 27.

Information content for BTA 2, 7, and 27 was computed as described by Spelman et al. (1996). Interval mapping accounting for missing marker genotypes was performed by the algorithm of Spelman et al. (1996). Each family with a significant contrast was analyzed

Table 4. Means, standard deviations, and minimum and maximum values of estimated breeding values of the cows genotyped for the traits analyzed.

\begin{tabular}{lcccc}
\hline Trait & Mean & SD & Minimum & Maximum \\
\hline Milk (kgs) & 209.9 & 478.0 & -1329.0 & 2101.8 \\
Fat (kgs) & 6.82 & 14.64 & -47.83 & 63.59 \\
Protein (kgs) & 3.11 & 10.88 & -31.87 & 46.45 \\
Percent fat & 0.003 & 0.168 & -0.571 & 0.610 \\
Percent protein & -0.028 & 0.093 & -0.356 & 0.218 \\
SCS & -0.081 & 0.213 & -0.883 & 0.730 \\
Herd-life (days) & 149.7 & 108.3 & -207.7 & 501.2 \\
Percent conception & -0.069 & 2.85 & -7.44 & 9.62 \\
\hline
\end{tabular}


Table 5. Correlations among the estimated breeding values of the cows genotyped for the traits analyzed.

\begin{tabular}{|c|c|c|c|c|c|c|c|}
\hline Trait & Fat $(\mathrm{kg})$ & Protein $(\mathrm{kg})$ & Percent fat & Percent protein & SCS & Herd-life (d) & Percent conception \\
\hline Milk (kg) & 0.268 & 0.704 & -0.627 & -0.645 & 0.169 & 0.266 & -0.296 \\
\hline Fat (kg) & & 0.281 & 0.582 & -0.072 & -0.229 & 0.208 & 0.151 \\
\hline Protein (kg) & & & -0.370 & 0.088 & 0.167 & 0.233 & -0.275 \\
\hline Percent protein & & & & & -0.057 & -0.123 & 0.121 \\
\hline SCS & & & & & & -0.309 & -0.356 \\
\hline Herd-life (d) & & & & & & & 0.346 \\
\hline
\end{tabular}

separately. Ninety-five percent confidence intervals (CI95) for the QTL location and effect were determined by the bootstrap method (Visscher et al., 1996; Ron et al, 2001). Finally, as proposed by Weller et al. (1996), canonical variables were derived from the milk, fat, and protein evaluations for the cows genotyped on BTA 7; and interval mapping on the canonical variables was performed, as described.

\section{RESULTS}

Two chromosome regions were found with genomewide significance on at least one trait, the central region of BTA 6 on protein percent, and the centromeric region of BTA 14 on fat percent. Both of these regions have been described in detail in previous studies in several different populations (Ron et al., 2001; Grisart et al., 2002; Weller et al., 2003). The FDR was then computed for each trait with the 4 markers located in these regions deleted. The number of markers with significant effects with the FDR controlled at 0.4, considering each trait separately, is given in Table 7. In this case the total number of tests is the number of markers genotyped. The trait heritabilities and the marker with the highest significant comparison-wise probability with the FDR controlled at 0.4 are also given. By the nature

Table 6. The map locations of the markers genotyped for interval mapping of significant QTL effects, the number of heterozygous sires genotyped per marker, and the number of informative daughters per marker.

\begin{tabular}{|c|c|c|c|c|c|}
\hline \multirow[b]{2}{*}{ BTA $^{1}$} & \multirow[b]{2}{*}{ Locus $^{2}$} & \multicolumn{2}{|c|}{ Map location (cM) } & \multirow{2}{*}{$\begin{array}{l}\text { Heterozygous } \\
\text { sires }\end{array}$} & \multirow{2}{*}{$\begin{array}{l}\text { Informative } \\
\text { daughters }\end{array}$} \\
\hline & & 3 & 4 & & \\
\hline \multirow[t]{9}{*}{2} & ETH121 & 34 & 34 & 9 & 1573 \\
\hline & BMS1126 & 56 & 61.4 & 6 & 1238 \\
\hline & RMN041* & 69 & 68.3 & 2 & 712 \\
\hline & BMS1987* & 98.2 & 120.3 & 1 & 472 \\
\hline & BMS2519* & 101.5 & 144.3 & 2 & 637 \\
\hline & BMS2113 & 106.2 & 150.6 & 9 & 2413 \\
\hline & IDVGA37* & 108.2 & 153.5 & 1 & 359 \\
\hline & IDVGA2 & 117.8 & 167.6 & 1 & 263 \\
\hline & FCB11* & 120.4 & 169.9 & 1 & 345 \\
\hline \multirow[t]{10}{*}{7} & BM7160 & 0 & 0 & 1 & 251 \\
\hline & BMS713* & 15.2 & 12.9 & 1 & 207 \\
\hline & BM6105 & 35.7 & 35.8 & 1 & 226 \\
\hline & TGLA303* & 38.5 & 49.7 & 1 & 251 \\
\hline & BM7247 & 58.0 & 69.5 & 1 & 120 \\
\hline & UWCA20* & 59.9 & 71.8 & 7 & 1909 \\
\hline & BMS2840* & 69 & 94.8 & 1 & 297 \\
\hline & INRA112 & 72.1 & 101.5 & 1 & 268 \\
\hline & BMS792 & 76.9 & 103.9 & 1 & 196 \\
\hline & BMS1331 & 91.1 & 114.7 & 1 & 207 \\
\hline \multirow[t]{7}{*}{27} & BMS2168 & 0 & 0 & 6 & 1509 \\
\hline & BMS641 & 14.3 & 15.6 & 1 & 430 \\
\hline & BMS689* & 34.1 & 26.2 & 7 & 2160 \\
\hline & CSSM $36^{*}$ & 39.8 & 35.4 & 1 & 506 \\
\hline & BM1857* & 52.7 & 38.6 & 1 & 380 \\
\hline & INRA027 & 58.4 & 44.9 & 1 & 349 \\
\hline & BM203 & 64.1 & 52.9 & 1 & 321 \\
\hline
\end{tabular}

${ }^{1}$ Bos taurus autosome.

${ }^{2}$ Markers with significant effects on at least one trait are denoted by an asterisk.

${ }^{3}$ From the Clay Center genetic map (http://sol.marc.usda.gov/genome/cattle/cattle.html).

${ }^{4}$ Analysis of the results of this study by Crimap (http://linkage.rockefeller.edu /soft/crimap). 
Table 7. The number of markers with significant effects with the FDR controlled at 0.4 when each trait was analyzed separately.

\begin{tabular}{llll}
\hline & Heritability & $\begin{array}{l}\text { Number of } \\
\text { significant } \\
\text { markers }\end{array}$ & $\begin{array}{l}\text { Highest nominal } \\
\text { probability } \\
\text { for significance }\end{array}$ \\
\hline Milk $(\mathrm{kg})$ & Hait $^{2}$ & 12 & 0.059 \\
Fat $(\mathrm{kg})$ & 0.25 & 6 & 0.028 \\
Protein $(\mathrm{kg})$ & 0.35 & 4 & 0.013 \\
Percent fat & 0.24 & 18 & 0.103 \\
Percent protein & 0.5 & 8 & 0.040 \\
SCS & 0.6 & 5 & 0.025 \\
Herd-life (d) & 0.16 & 8 & 0.045 \\
Percent conception & $0.12^{3}$ & 0 & - \\
\hline
\end{tabular}

${ }^{1}$ Heritability values are from Weller and Ezra (1997), unless otherwise indicated.

${ }^{2}$ Probability of the marker effect nested within sire from the ANOVA analysis of all families with heterozygous sires.

${ }^{3}$ From Settar and Weller (1999).

of the FDR, the highest significant comparison-wise probability increases as the number of effects deemed "significant" increases. The number of significant marker effects ranged from zero for conception rate to 18 for fat percent. Weller et al. (1990) predicted that for both daughter and granddaughter designs the number of detectable QTL per trait should increase as a function of the heritability, and the correlation between these two statistics was 0.61 . However, there were only 8 significant effects for protein percentage, even though this trait has the highest heritability. No significant effects were found for conception rate with the FDR controlled at either 0.4 or 0.5 , and this trait was deleted from all further analyses. The heritability of conception rate is only 0.03 (Weller and Ezra, 1997), and, therefore, it is very unlikely that a segregating QTL could be detected with the current experiment size. The FDR was then computed jointly for the remaining 483 marker $\times$ trait combinations (69 markers $\times 7$ traits).

The FDR computed with all traits analyzed jointly up to 0.5 is plotted in Figure 1 as a function of the number of tests with the tests ordered by probability. The comparison-wise probabilities are also given. There were 40 marker-trait combinations with FDR controlled at 0.4. Thus it is expected that approximately 24 of these are true effects. The highest comparisonwise probability for which the FDR was controlled at 0.4 was 0.031 . With the FDR controlled at 0.5 , there were 63 significant effects, and the highest comparisonwise probability was 0.06 . In this case, it is expected that about 31.5 of these effects are real. Increasing the FDR to 0.5 doubled the nominal "significance" probability, but only increased the expected number of true effects by 7.5. The expected number of real effects was at a maximum with the FDR controlled at 0.64. In this case, 195 marker-trait combinations are deemed "significant," the comparison-wise probability is 0.26 , and 70 marker-trait combinations should represent true effects. Thus, by controlling the FDR at 0.4 about one third of all true effects were probably detected. Therefore, only effects deemed significant with the FDR controlled at 0.4 were retained for further analyses.

The ANOVA probability values of significant markertrait combinations by chromosome and trait with the FDR controlled at 0.4 , and all traits analyzed jointly are given in Table 8. The significant effects on BTA 6 and 14 are also given, even though the markers on these chromosomes were deleted from the FDR computation. If more than one marker-trait combination was significant per chromosome, then the marker-trait combination with the lowest ANOVA probability is given. This occurred for protein percentage on BTA 15 and SCS on BTA 12. Similar to the single-trait FDR analyses, there were significant effects on all traits included

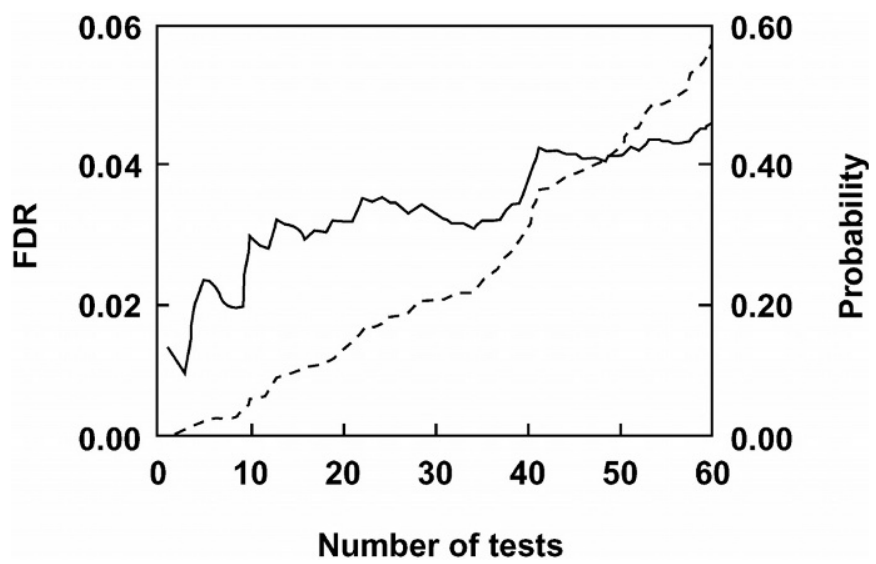

Figure 1. The false discovery rate (FDR) computed with all traits analyzed jointly as a function of the number of tests with the tests ordered by probability. -, FDR; - --, nominal ANOVA probability values. 
RON ET AL.

Table 8. ANOVA probability values of significant marker-trait combinations by chromosome and trait with the FDR controlled at 0.4 , and all traits analyzed jointly. ${ }^{1}$

\begin{tabular}{|c|c|c|c|c|c|c|c|}
\hline \multirow[b]{2}{*}{$\mathrm{BTA}^{2}$} & \multicolumn{7}{|c|}{ Trait } \\
\hline & Milk & Fat & Protein & $\%$ Fat & $\%$ Protein & SCS & Herd-life \\
\hline 2 & & 0.0090 & 0.0005 & 0.0096 & & & \\
\hline 3 & & & 0.0095 & 0.0213 & 0.0024 & & \\
\hline 4 & & & & 0.0309 & 0.0125 & & \\
\hline 5 & 0.0268 & & 0.0130 & & & & \\
\hline $6^{3}$ & $10^{-5}$ & & & $10^{-11}$ & $10^{-14}$ & & \\
\hline 7 & 0.0035 & 0.0006 & 0.0032 & & & & 0.0061 \\
\hline 8 & 0.0215 & & & 0.0016 & 0.0112 & & \\
\hline 9 & & & & 0.0237 & & & \\
\hline 10 & & & & & 0.0028 & & 0.0086 \\
\hline 11 & & & & & & & 0.0174 \\
\hline 12 & & & & & & 0.0196 & \\
\hline $14^{3}$ & 0.0053 & $10^{-5}$ & & $10^{-13}$ & $10^{-5}$ & & \\
\hline 15 & & 0.0276 & & 0.0137 & 0.0068 & & \\
\hline 16 & 0.0160 & & & & & & \\
\hline 18 & & 0.0029 & & & & & \\
\hline 19 & & & & & & 0.0183 & \\
\hline 20 & & & & 0.0177 & & 0.0064 & \\
\hline 24 & & 0.0205 & & 0.0107 & & & \\
\hline 25 & 0.0200 & & & & & & 0.0163 \\
\hline 26 & & & & & 0.0003 & & \\
\hline 27 & & 0.0202 & & & & & \\
\hline 28 & & & & & & 0.0232 & \\
\hline 29 & & & & & & & 0.0182 \\
\hline
\end{tabular}

in the multitrait analysis. There were significant effects on all chromosomes, except for BTA 1, 13, 17, 21, 22, and 23 .

In addition to BTA 6 and 14, there were three chromosomes with nominal ANOVA comparison-wise probabilities below 0.001: 2, 7, and 26. There were 4 families with significant contrasts on BTA 2, 2 families with significant contrasts on BTA 7, and two families with significant contrasts on BTA 26 . We have prioritized our interval mapping efforts according to the economic value of the QTL. Thus, interval mapping has not yet been performed for BTA 26, which apparently has minimal economic value. Interval mapping was performed on BTA 27, even though it did not meet the significance level of 0.001 , because the probability of preliminary results was lower. There were 3 families with significant contrast on this chromosome. The interval mapping plots of the traits with significant contrasts for BTA 2, 7, and 27 are given in Figures 2, 3, and 4, respectively. Only a single sire family was analyzed for each chromosome, but a different family was analyzed for each chromosome. The QTL effects on a specific trait were considered significant if the absolute value of maximum QTL effect was more than twice the standard

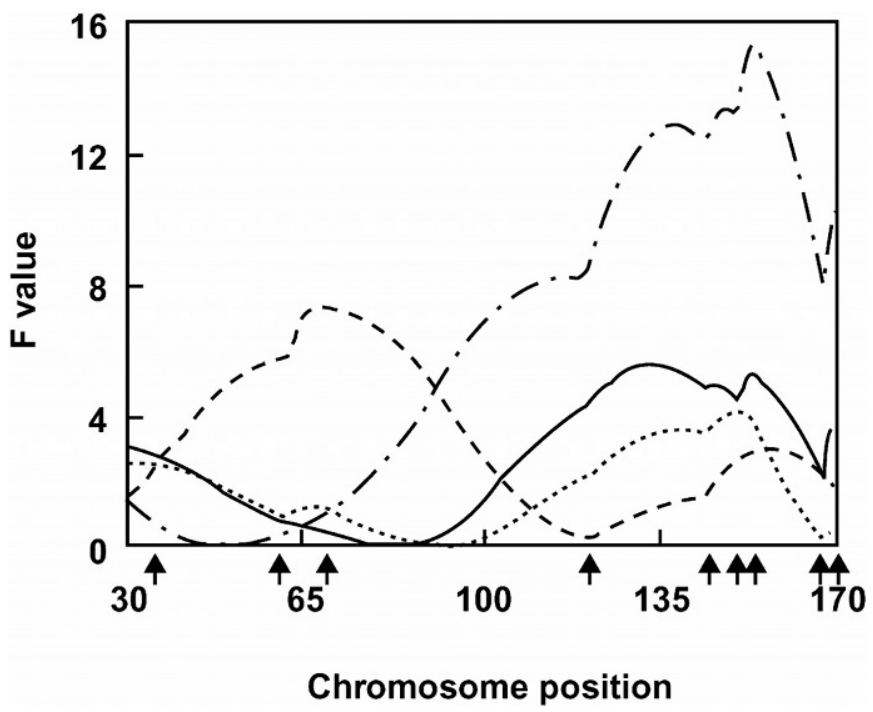

Figure 2. Interval mapping on chromosome 2 of traits with significant effects in the daughters of sire 3070. - , milk; - - -, protein; $\cdots$, fat percent; - - - protein percent. Markers positions are denoted by arrows. 


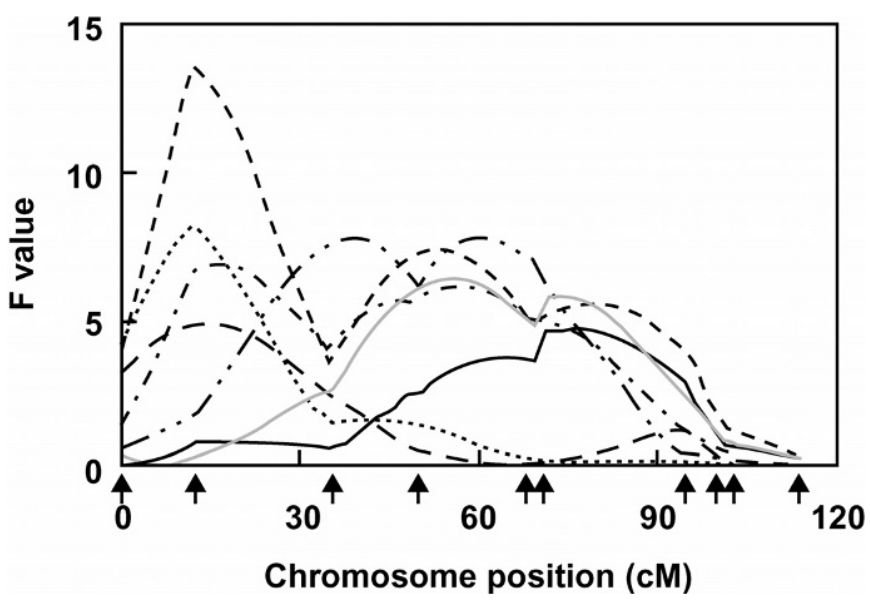

Figure 3. Interval mapping on chromosome 7 of production traits with significant effects in the daughters of sire 2357. -, milk; - - -, fat; - - - , protein; $\cdots$, fat percent; - - - protein percent; - - - -, somatic cell score; gray curve, herd-life. Markers positions are denoted by arrows.

error. This is approximately equivalent to an $F$ value of 4 .

A major QTL affecting protein and milk production is evident at the end of BTA 2 near position $150 \mathrm{cM}$. A second QTL affecting protein percent is apparently located near position $70 \mathrm{cM}$. Significant effects on all traits analyzed, except fertility were found on BTA 7. A major QTL located near position $15 \mathrm{cM}$ affects fat and protein yield, and fat and protein percent, whereas a second QTL located near position $60 \mathrm{cM}$ affects milk, fat, and protein yield, but not fat or protein concentration. In addition, significant effects were found for both

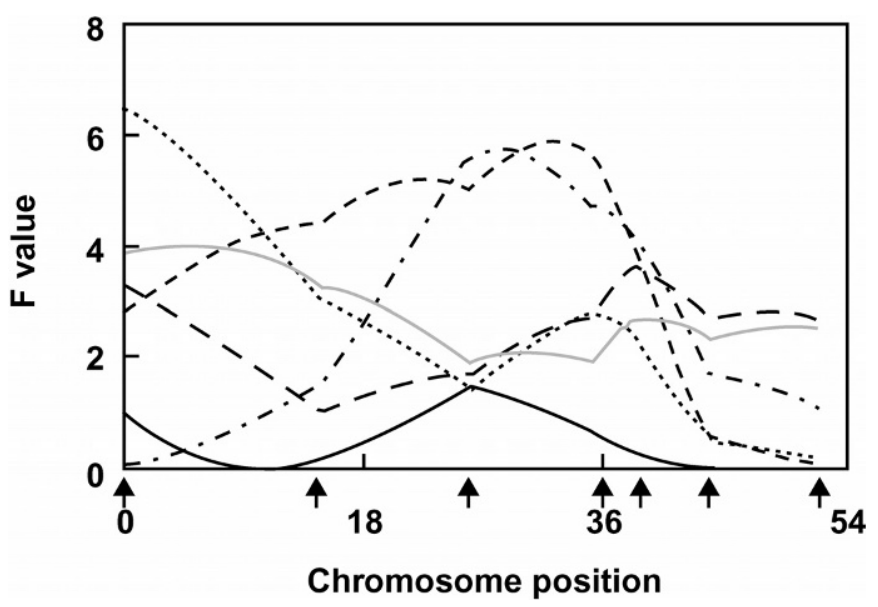

Figure 4. Interval mapping of chromosome 27 of traits with significant effects in the daughters of sire 3241. - , milk; - - -, fat; - - -, protein; $\cdots$, fat percent; - - - protein percent; gray curve, herd-life. Markers positions are denoted by arrows.

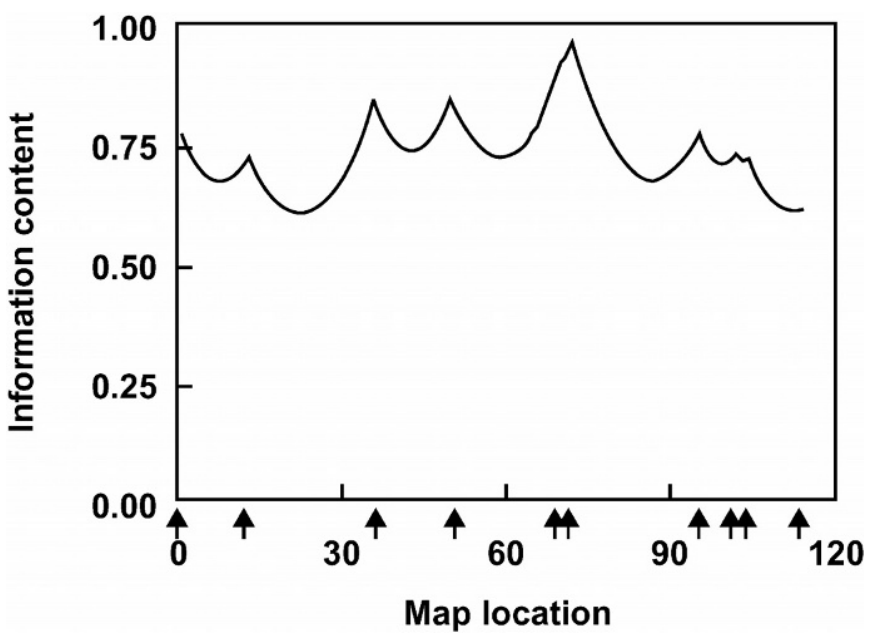

Figure 5. Information content as a function of map location on chromosome 7 for the daughters of sire 2357. Markers positions are denoted by arrows.

SCS and herd-life near position $60 \mathrm{cM}$. The test statistic profile for SCS also appears to be bimodal, but this might be due to the bias inherent in interval mapping (Weller, 2001). In the vicinities of QTL, $F$-values at marker locations tend to be lower than at intervals between markers. This may account for the lower $F$ value near marker TGLA303 at position $49.7 \mathrm{cM}$ (38.5 on the Clay Center map). On BTA 27 significant effects were found for fat and protein production near position $30 \mathrm{cM}$, and for fat and protein concentration near position $0 \mathrm{cM}$. No significant effects were found for milk

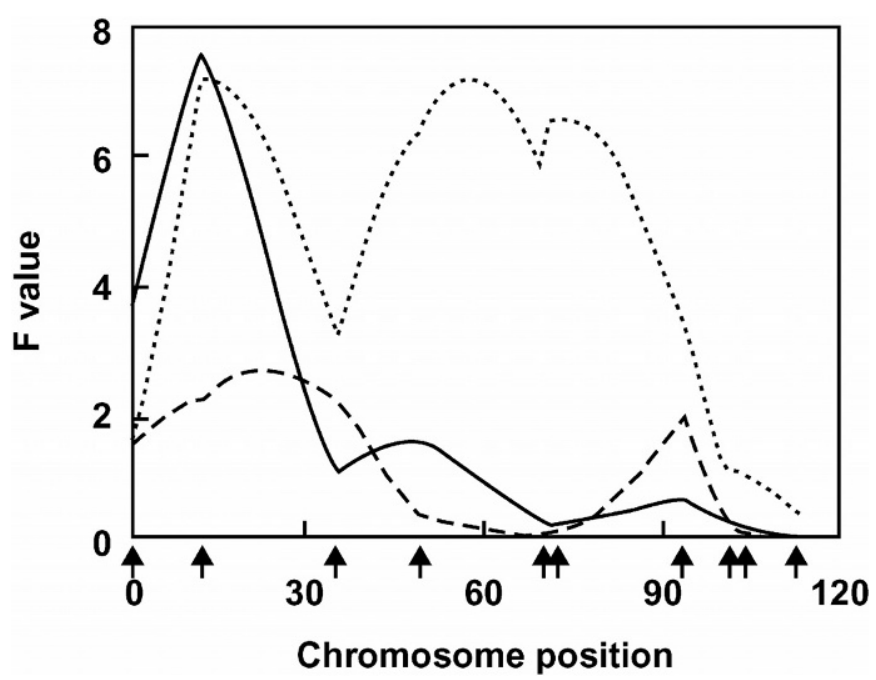

Figure 6. Interval mapping on chromosome 7 of the canonical variables for the three milk production traits. - , variable $1 ;---$ variable $2 ; \cdots$, variable 3 . Markers positions are denoted by arrows. 
RON ET AL.

Table 9. The locations of the test statistic peaks, the test statistic values at the peaks, and the estimated substitution effects at the peaks for QTL on BTA 2,7 , and $27 .{ }^{1}$

\begin{tabular}{|c|c|c|c|c|c|}
\hline $\mathrm{BTA}^{2}$ & Sire & Trait & $\begin{array}{l}\text { Peak } \\
\text { location } \\
(\mathrm{cM})\end{array}$ & $\begin{array}{l}\text { Test } \\
\text { statistic }\end{array}$ & $\begin{array}{l}\text { Substitution } \\
\text { effect } \\
\text { (in trait units) }\end{array}$ \\
\hline \multirow[t]{4}{*}{2} & \multirow[t]{4}{*}{3070} & Milk yield (kg) & 133 & 5.6 & 88 \\
\hline & & Protein yield $(\mathrm{kg})$ & 153 & 15.4 & 3.0 \\
\hline & & Fat $\%$ & 151 & 4.2 & -0.010 \\
\hline & & Protein \% & 68 & 7.4 & 0.015 \\
\hline \multirow[t]{7}{*}{7} & \multirow[t]{7}{*}{2357} & Milk yield $(\mathrm{kg})$ & 76 & 4.6 & 83 \\
\hline & & Fat yield (kg) & 12 & 13.6 & 5.1 \\
\hline & & Protein yield (kg) & 17 & 6.8 & 2.9 \\
\hline & & Fat $\%$ & 12 & 8.2 & 0.036 \\
\hline & & Protein \% & 14 & 4.8 & 0.016 \\
\hline & & SCS & 39 & 7.8 & -0.046 \\
\hline & & Herd-life (days) & 55 & 6.4 & 23.8 \\
\hline \multirow[t]{4}{*}{27} & \multirow[t]{4}{*}{3241} & Fat yield (kg) & 32 & 5.9 & 2.9 \\
\hline & & Protein yield $(\mathrm{kg})$ & 28 & 5.7 & 2.0 \\
\hline & & Fat $\%$ & 0 & 6.5 & 0.030 \\
\hline & & Herd-life (days) & 5 & 4.0 & 16.6 \\
\hline
\end{tabular}

${ }^{1}$ Effects are included only if the peak substitution effect was more than twice its standard error.

${ }^{2}$ Bos taurus autosome.

production. A marginally significant effect was found for herd-life near the beginning of the chromosome.

The locations of the test statistic peaks, the test statistic values at the peaks, and the estimated substitution effects at the peaks are given in Table 9 for the significant effects. Although the direction of the effects is arbitrary, consistency was maintained within each family. That is if one of the paternal chromosomes was associated with an increase in one trait and a decrease in a second trait, the magnitudes of the two effects are listed with opposite signs. Because EBV were analyzed, the estimates of the substitution effects are regressed, although this does not affect the power of detection (Israel and Weller, 1998).

Bootstrap means and confidence intervals for QTL effect and location for the significant effects are given in Table 10. Confidence intervals are given only for traits for which the CI95 for QTL effect did not include zero (Ron et al., 2001). Generally if the CI95 for QTL effect included zero, the CI95 for QTL location included the entire chromosome. There were only 4 chromosometrait combinations that met this criterion, one on BTA
2 and three on BTA 7. The bootstrap means for QTL effect were in all cases quite close to the interval mapping results given in Table 9. The CI95 for QTL location ranged from $65 \mathrm{cM}$ for SCS on BTA 7 to $127 \mathrm{cM}$ for protein percent on BTA 2. On BTA 7, the CI95 for QTL location included most of the chromosome, and overlapped for the 3 traits with significant effects. Although SCS on BTA 7 had the smallest CI95, the $F$ value for this trait was lower than for fat yield on BTA 7. The CI95 for protein yield on BTA 2 included the entire chromosome, because of a few points with very low values for QTL location. The limits for the $90 \%$ CI were 100 and $169 \mathrm{cM}$. Likewise, $75 \%$ of the points for QTL location for fat yield and percent fat on BTA 7 were between positions 0 and $21 \mathrm{cM}$.

Information content as a function of chromosome location is plotted in Figure 5 for BTA 7. Information content is highest near position 70 and lowest at positions 25 and at the end of the chromosome, but generally differences between positions were small. Thus, the QTL test statistic should not be significantly biased by differences in information content. Similar results were

Table 10. Bootstrap means and confidence intervals for QTL effect and location for the significant effects on Bos taurus autosomes (BTA) 2 and $7 .^{1}$

\begin{tabular}{llllllll}
\hline & & & \multicolumn{2}{c}{$\begin{array}{c}\text { Substitution effect } \\
\text { (in trait units) }\end{array}$} & & \multicolumn{2}{c}{$\begin{array}{c}\text { Peak location } \\
\text { (cM) }\end{array}$} \\
\cline { 4 - 5 } BTA & Sire & Trait & Mean & CI95 & & Mean & CI95 \\
\hline 2 & 3070 & Protein \% & 0.018 & $0.008-0.029$ & & 86 & $40-167$ \\
7 & 2357 & Fat yield (kg) & 5.3 & $2.8-7.9$ & & 27 & $12-93$ \\
& & Protein yield (kg) & 3.2 & $1.4-5.2$ & & 39 & $12-95$ \\
& SCS & -0.050 & $-0.019-(-0.081)$ & & 51 & $24-89$ \\
\hline
\end{tabular}

${ }^{1}$ Effects are included only if the confidence interval for the substitution effect did not include zero. 
Table 11. Eigenvectors and eigenvalues for the production traits of the daughters of sire $2357 .{ }^{1}$

\begin{tabular}{lllr}
\hline & \multicolumn{3}{c}{ Trait } \\
\cline { 2 - 4 } & Milk & Fat & Protein \\
\hline Eigenvectors & -0.515 & 0.833 & -0.201 \\
& 0.623 & 0.203 & -0.755 \\
Eigenvalues & 0.588 & 0.514 & 0.624 \\
\hline
\end{tabular}

${ }^{1} \mathrm{~A}$ total of 508 cows with evaluations for production records and at least one valid genotype on BTA 7 are included in the analysis.

obtained for BTA 7 and 27, and are therefore not presented.

The eigenvectors and eigenvalues for production traits of the daughters of sire 2357 are given in Table 11 , and the correlations between the canonical variables and the milk production traits are given in Table 12. The third canonical variable loads positively on all 3 production traits and has an eigenvalue of 2.2. Thus it explains $74 \%$ of the total variance. The first canonical variable has a positive correlation with fat, and a negative correlation with milk, whereas the second canonical variable, which explains only $7 \%$ of the variance, has a positive correlation with milk, but a negative correlation with protein. The interval mapping plots for the 3 canonical variables are given in Figure 6 . Variable 1, which corresponds approximately to fat concentration, has a clear maximum near position $13 \mathrm{cM}$, whereas variable 3 , which corresponds roughly to total production, has two peaks, near positions 15 and 60 cM. Variable 2, which corresponds roughly to protein concentration did not have a significant maximum. These results support the previous results on the actual traits that two QTL affecting production traits are segregating on chromosome 7 .

\section{DISCUSSION}

Five years was required to complete the genome scan of the Israeli Holstein population by a daughter design with individual genotyping of all animals. One to five markers per chromosome were analyzed for each of the 29 autosomes of cattle. Maximal distance in map units was 53 between markers, and 50 between a marker

Table 12. Correlations between the milk production traits and the canonical variables for the daughters of sire 2357 .

\begin{tabular}{lllr}
\hline & \multicolumn{3}{c}{ Trait } \\
\cline { 2 - 4 } Canonical variables & Milk & Fat & Protein \\
\hline 1 & -0.394 & 0.638 & -0.154 \\
2 & 0.281 & 0.092 & -0.342 \\
3 & 0.875 & 0.765 & 0.927 \\
\hline
\end{tabular}

and chromosome end. The use of robotics and the appropriate software were essential for processing thousands of samples and genotypes. Over 160,000 genotypes of 6000 cows were determined, and more than 86,000 individual genotypes were included in the QTL analysis. The most labor-intensive and time-consuming phase was the preparation of the infrastructure, including blood sampling, DNA extraction, and optimization of the different panels of markers. We recently developed an efficient method for genotyping large numbers of DNA samples derived from vaginal swabs (Ron et al., 2003). DNA extraction from blood samples is replaced with cell lysis. Unlike blood sampling, which requires puncture of the cow's vein by veterinarian; sampling by vaginal swabs can be done by insemination technicians after minimal instruction. Application of this method should significantly reduce genotyping costs in daughter design analyses.

If genotyping cost is the only limiting factor, Darvasi and Soller (1994) found that optimum marker spacing for a backcross design was $80 \mathrm{cM}$ between markers, assuming the Haldane mapping function. The daughter design is similar to a backcross design analyzed by Darvasi and Soller (1994), except that they assumed that only a single family was analyzed and that all genotypes are informative. In daughter and granddaughter designs, only a fraction of the sires will be heterozygous for any particular marker, and not all genotypes are informative. Thus the optimum marker spacing is likely to be smaller than for the backcross design, although this question has not been rigorously analyzed. We therefore set our objective to obtain a maximum marker spacing of $50 \mathrm{cM}$.

The mean number of heterozygous sires per marker was $5.9(69 \%)$, and the mean number of informative genotypes per marker was 1182 . Statistical power with this design to detect a QTL with a substitution effect of 0.3 phenotypic standard deviations and two alleles at equal frequency is approximately $70 \%$, with a type I error rate of 0.05 , and $50 \%$ with a type I error rate of 0.01 (Weller et al., 1990). Thus, a significant fraction of QTL of this magnitude should not have been detected. The power of the experimental design is actually slightly higher, because, except for herd-life, the cows generally had multiple records. It is not surprising that no QTL were detected for conception rate, because a QTL of this magnitude would explain 0.045 of the phenotypic variance, which is more than the total genetic variance for this trait (Weller et al., 1990; Weller and Ezra, 1997).

As noted by Israel and Weller (1998), estimates of QTL effects derived from analysis of genetic evaluations are biased, because genetic evaluations are regressed. Most granddaughter designs studies have analyzed 
daughter-yield-deviations, which are unregressed, relative to the genetic evaluations (VanRaden and Wiggans, 1991), but EV and deregressed proofs have also been analyzed (Thomsen et al., 2001). In the daughter design, the comparable statistic would be yield deviations. Israel and Weller (1998) showed that estimates of QTL effects derived by analysis of either daughter-yield-deviations or yield deviations are still biased, although less so than genetic evaluations. They also showed that unbiased estimates of QTL effects could be obtained if the QTL effect was included in the animal model analysis even though only a small fraction of the population was actually genotyped. We plan to perform this analysis in a future study. Israel and Weller (1998) demonstrated that statistical power of detection was not affected by the choice of the dependent variable, whereas Thomsen et al. (2001) in a granddaughter design analysis found that power of detection was lower for EBV than for either DYD or deregressed evaluations. Preliminary analyses showed that virtually identical results were obtained in both the preliminary QTL analysis and interval mapping if the EBV were weighted by their reliabilities. This is not surprising, considering that the standard deviation of the reliabilities was only $6.5 \%$ of the mean. Again, Thomsen et al. (2001) found different results, but, in their study, the number of sons per sire ranged from 19 to 127.

Israel and Weller (1998) found that the estimated effect by analysis of genetic evaluations for a trait with a heritability of 0.25 was approximately equal to 0.4 of the simulated effect. In this case, the actual substitution effect on fat yield on BTA 7, the effect with the highest test statistic in the interval mapping analysis, would be approximately $13 \mathrm{~kg}$. This value can be compared to the genetic and phenotypic standard deviations of approximately 26 and $48 \mathrm{~kg}$ for fat yield derived from a REML analysis of the Israeli population (unpublished data). In this case the effect on BTA 7 would be equal to 0.5 genetic or 0.27 phenotypic standard deviations. There were significant within-family contrasts for only two bulls of the seven bulls analyzed. Assuming that only two alleles are segregating for the QTL and that the frequency of heterozygotes is $2 / 7=$ 0.29 , a QTL of this magnitude would explain approximately $7 \%$ of the genetic variance (Weller et al., 1990).

Georges et al. (1995) noted that if many marker-trait combinations are analyzed, those effects deemed "significant" would tend to be overestimated, especially for effects that were only marginally significant. As also shown by Georges et al. (1995), this "selection" effect should be marginal for the QTL affecting fat yield on BTA 7, which was significant at $P<0.001$.

By controlling the FDR at 0.4 to determine significance, it is clear that several of the significant effects are in fact false positives. Evidence to support the results presented can be obtained by comparison to other dairy cattle analyses, especially those applied to Holsteins. Ashwell et al. (2001) analyzed the US Holstein population by a granddaughter design for 155 markers. They found significant effects on BTA 6 for protein percent, but did not find significant effects on production traits on BTA 2, 7, 26, or 27. Plante et al. (2001) analyzed 10 Holstein chromosomes, but their analysis did not include BTA 2, 7, or 27. They did not find a significant effect for protein percent on BTA 26. Heyen et al. (1999) found significant effects on BTA 2 for protein percent; and on BTA 7 for milk yield, protein yield, and SCS. However, the effects found on BTA 7 were near the opposite end of the chromosome. Zhang et al. (1998) found a highly significant effect on protein percent on BTA 6, and significant effects for fat percent and SCS on BTA 26 , but not for protein percent.

Mosig et al. (2001) analyzed protein percent in the Israeli Holstein population by sample pooling. Although the same population was analyzed, there was only partial overlap between the markers and families analyzed. They found significant effects on all bovine autosomes, except for 15, 25, and 28; and for 61 of the 138 markers they analyzed. The identified QTL in their study were claimed to account for approximately all the variation in protein percent EBV. Significant effects for protein percent found on BTA $3,4,6,8,10$, and 26 in the current study were also found in the previous study. However, the highly significant effects found for the QTL on BTA 14 and 15 in the current study were not detected by Mosig et al. (2001). In conclusion, the significant effects found in this study on BTA 2, 7, 26, and 27 were not collaborated by independent studies in this or other populations.

As shown previously by Ron et al. (2001) and noted by Bennewitz et al. (2002), the criterion that the bootstrap CI95 for QTL effect should exclude zero, is quite conservative. It was not possible to determine CI95 by the bootstrap method for three effects that were significant at the nominal level of 0.01. The CI95 for QTL location were all at least $65 \mathrm{cM}$. Therefore, it is unlikely that these CI can be significantly reduced even if more markers are genotyped, unless additional animals are also genotyped (Darvasi and Soller, 1997). In addition, there were apparently multiple QTL segregating on all three chromosomes. The bootstrap method applied was based on the assumption that only a single QTL is segregating on each chromosome for each trait analyzed.

There are apparently at least two QTL segregating on BTA 7 affecting fat and protein production. Both the test statistic profiles and the bootstrap distributions for QTL location were bimodal for these traits. The QTL close to the beginning of the chromosome apparently 
affects fat and protein yield, but not milk yield, and therefore also affects fat and protein concentration. The second QTL near the middle of the chromosome apparently affects milk, fat, and protein yield in the same direction, but does not affect fat or protein concentration. By analysis of additional families, it should be possible to determine whether in fact multiple QTL are segregating on this chromosome (Ron et al., 2001). If multiple QTL are segregating in the Israeli population on this chromosome, and sire 2357 is heterozygous for all of these QTL, it is unlikely that other sires will also be heterozygous for exactly the same QTL, considering that most individuals are homozygous for any specific QTL.

Recently, using bioinformatics, single nucleotide polymorphisms, and DNA sequencing, the genomic region underlying the segregating QTL on BTA 14 in the Israeli, US, and Dutch Holstein populations was identified (Grisart et al., 2002; Weller et al., 2003). It should therefore be possible to identify genes underlying QTL of smaller magnitude, if larger samples of animals are genotyped. Because the number of progeny tested sires is limited, even in the largest commercial populations, it will be necessary to apply a daughter design for QTL of smaller magnitudes to reduce the CI for QTL location to the length for which positional cloning becomes possible.

There were a total of 11 family $\times$ marker combinations with significant within-family contrasts for the QTL detected on BTA 2, 7, 26, and 27 out of 33 families analyzed. The value of $33 \%$ mean heterozygous families is in accordance with previous studies (Georges et al., 1995; Mosig et al., 2001; Ron et al., 2001), and is consistent with the hypothesis that only two phenotypically different QTL alleles are segregating with unequal frequency. To evaluate the expected response from MAS for a given QTL, it is imperative to estimate the frequency of the QTL allele with the favorable economic effect. If the functional mutation of a gene underlying the QTL is discovered, the allele frequency can be directly analyzed. The frequency of the DGAT1 K allele on BTA 14 that increases fat concentration was estimated at $12 \%$ in the Israeli cow population (Weller et al., 2003).

If the functional QTL has not been identified, QTL allelic frequencies in the population can be estimated as proposed by Weller et al. (2002) via the modified granddaughter design. They found that the QTL allele near the center of BTA 6 , which increases protein and fat concentration and decreases milk production, is at a relatively high frequency (0.6) in the Israeli cow population. Therefore, the potential gain via MAS for this QTL in Israel is limited.

\section{ACKNOWLEDGMENTS}

This research was supported by a grant from the Israel Milk Marketing Board and the US-Israel Binational Agricultural Research and Development fund (BARD). We thank R. J. Spelman for the use of his interval-mapping program. We thank all the herd managers in Israel who allowed us to collect blood from their cows.

\section{REFERENCES}

Ashwell, M. S., C. P. Van Tassell, and T. S. Sonstegard. 2001. A genome scan to identify quantitative trait loci affecting economically important traits in a US Holstein population. J. Dairy Sci. 84:2535-2542.

Benjamini, Y., and Y. Hochberg. 1995. Controlling the false discovery rate: A practical and powerful approach to multiple testing. J. R. Statist. Soc. B. 57:289-300.

Bennewitz, J., N. Reinsch, and E. Kalm. 2002. Improved confidence intervals in quantitative trait loci mapping by permutation bootstrapping. Genetics 160:1673-1686.

Crawford, A. M., and R. P. Cuthbertson. 1996. Mutations in sheep microsatellites. Genome Res. 6:876-879.

Darvasi, A., and M. Soller. 1994. Optimum spacing of genetic markers for determining linkage between marker loci and quantitative trait loci. Theor. Appl. Genet. 89: 351-357.

Darvasi, A., and M. Soller. 1997. A simple method to calculate resolving power and confidence interval of QTL map location. Behav. Genet. 27:125-132.

Georges, M., D. Nielsen, M. Mackinnon, A. Mishra, R. Okimoto, A. T. Pasquino, L. S. Sargent, A. Sorensen, M. R. Steele, X. Zhao, J. E. Womack, and I. Hoeschele. 1995. Mapping quantitative trait loci controlling milk production in dairy cattle by exploiting progeny testing. Genetics 139:907-920.

Grisart, B., W. Coppieters, F. Farnir, L. Karim, C. Ford, P. Berzi, N. Cambisano, M. Mni, S. Reid, P. Simon, R. Spelman, M. Georges, and R. Snell. 2002. Positional candidate cloning of a QTL in dairy cattle: Identification of a missense mutation in the bovine DGAT1 gene with major effect on milk yield and composition. Genome Res. 12:222-231.

Heyen, D. W., J. I. Weller, M. Ron, M. Band, J. E. Beever, E. Feldmesser, Y. Da, G. R. Wiggans, P. M. VanRaden, and H. A. Lewin. 1999. A genome scan for QTL influencing milk production and health traits in dairy cattle. Physiol. Genom. 1:165-175.

Israel, C., and J. I. Weller. 1998. Estimation of candidate gene effects in dairy cattle populations. J. Dairy Sci. 81:1653-1662.

Knott, S. A., J. M. Elsen, and C. S. Haley. 1996. Methods for multiplemarker mapping of quantitative trait loci in half-sib populations. Theor. Appl. Genet. 93:71-80.

Lander, E. S., and L. Kruglyak. 1995. Genetic dissection of complex traits: Guidelines for interpreting and reporting linkage results. Nature Genet. 11:241-247.

Ma, R. Z., J. E. Beever, Y. Da, C. A. Green, I. Russ, C. Park, D. W. Heyen, R. E. Everts, S. R. Fisher, K. M. Overton, A. J. Teale, S. J. Kemp, H. C. Hines, G. Guerin, and H. A. Lewin. 1996. A male linkage map of the cattle (Bos taurus) Genome. J. Hered. 87:261-271.

Mosig, M. O., E. Lipkin, G. Khutoreskaya, E. Tchourzyna, M. Soller, and A. Friedmann. 2001. A whole genome scan for quantitative trait loci affecting milk protein percentage in Israeli-Holstein cattle, by means of selective milk DNA pooling in a daughter design, using an adjusted false discovery rate criterion. Genetics 157:1683-1698.

Plante, Y., J. P. Gibson, J. Nadesalingam, H. Mehrabani-Yeganeh, S. Lefebvre, G. Vandervoort, and G. B. Jansen. 2001. Detection of quantitative trait loci affecting milk production traits on 10 chromosomes in Holstein cattle. J. Dairy Sci. 84:1516-1524. 
Ron, M., Y. Blank, and M. Band. 1995. Determination of the optimal tissue source and number of microsatellites for detection of zygotic origin of cattle twins. Anim. Biotechnol. 6:27-37.

Ron, M., Y. Blank, M. Band, E. Ezra, and J. I. Weller. 1996. Misidentification rate in the Israeli dairy cattle population and its implications for genetic improvement. J. Dairy Sci. 79:676-681.

Ron, M., R. Domochovsky, M. Golik, E. Seroussi, E. Ezra, C. Shturman, and J. I. Weller. 2003. Analysis of vaginal swabs for paternity testing and marker-assisted selection in cattle. J. Dairy Sci. 86:1818-1820.

Ron, M., D. Kliger, E. Feldmesser, E. Seroussi, E. Ezra, and J. I. Weller. 2001. Multiple QTL analysis of bovine chromosome 6 in the Israeli Holstein population by a daughter design. Genetics 159:727-735.

Settar, P., and J. I. Weller. 1999. Genetic analysis of cow survival in the Israeli dairy cattle population. J. Dairy Sci. 82:2170-2177.

Spelman, R. J., W. Coppieters, L. Karim, J. A. M. van Arendonk, and H. Bovenhuis. 1996. Quantitative trait loci analysis for five milk production traits on chromosome six in the Dutch HolsteinFriesian population. Genetics 144:1799-1808.

Thomsen, H., N. Reinsch, N. Xu, C. Looft, S. Grupe, C. Kuhn, G. A. Brockmann, M. Schwerin, B. Leyhe-Horn, S. Hiendleder, G. Erhardt, I. Medjugorac, I. Russ, M. Forster, B. Brenig, F. Reinhardt, R. Reents, J. Blumel, G. Averdunk, and E. J. Kalm. 2001. Comparison of estimated breeding values, daughter yield deviations and de-regressed proofs within a whole genome scan for QTL. J. Anim. Breed. Genet. 118: 357-370.

VanRaden, P. M., and G. R. Wiggans. 1991. Derivation, calculation and use of national animal model information. J. Dairy Sci. 74:2737-2746.
Visscher, P. M., R. Thompson, and C. S. Haley. 1996. Confidence intervals in QTL mapping by bootstraping. Genetics 143:10131020 .

Weller, J. I. 2001. Quantitative Trait Loci Analysis in Animals. CABI Publishing. London, UK.

Weller, J. I., and E. Ezra. 1997. Genetic analysis of somatic cell concentration and female fertility of Israeli Holsteins by the individual animal model. J. Dairy Sci. 80:586-594.

Weller, J. I., M. Golik, E. Seroussi, E. Ezra, and M. Ron. 2003. Population-wide analysis of a QTL affecting milk-fat production in the Israeli Holstein population. J. Dairy Sci. 86:2219-2227.

Weller, J. I., C. Israel, and E. Ezra. 1994. A simple procedure for obtaining approximate interim cow solutions from an animal model. J. Dairy Sci. 77:1126-1131.

Weller, J. I., Y. Kashi, and M. Soller. 1990. Power of "daughter" and "granddaughter" designs for genetic mapping of quantitative traits in dairy cattle using genetic markers. J. Dairy Sci. 73:2525-2537.

Weller, J. I., J. Z. Song, D. W. Heyen, H. A. Lewin, and M. Ron. 1998. A new approach to the problem of multiple comparisons in the genetic dissection of complex traits. Genetics 150:1699-1706.

Weller, J. I., G. R. Wiggans, P. M. VanRaden, and M. Ron. 1996. Application of a canonical transformation to detection of quantitative trait loci with the aid of genetic markers in a multi-trait experiment. Theor. Appl. Genet. 92:998-1002.

Zhang, Q., D. Boichard, I. Hoeschele, C. Ernst, A. Eggen, B. Murkve, M. Pfister-Genskow, L. A. Witte, F. E. Grignola, P. Uimari, G. Thaller, and M. D. Bishop. 1998. Mapping quantitative trait loci for milk production and health of dairy cattle in a large outbred pedigree. Genetics 149:1959-1973. 